\section{Relationship between patronage and music a case study for the Ottoman archive documents}

\section{Patronaj ve müzik ilişkisi açısından Osmanlı arşiv belgeleri üzerine bir durum değerlendirmesi ${ }^{1}$}

\author{
Ahmet Feyzi ${ }^{2}$ \\ Hasan Tahsin Sümbüllü ${ }^{3}$
}

\begin{abstract}
This research focuses on art patronage and artist patronage in Turkish music culture in general and tries to provide an overview of Ottoman archival documents on the subject of patronage applied both to public and non-public musicians throughout the history of Turkish music.

The subject of patronage, which is of great importance in the development of the art of music in Turkish history, has been handled within the scope of the research and archive documents regarding the reflection of the patronage practice in the history of music have been gathered together. Based on these documents; firstly, it has been tried to clarify which practices are made within the scope of patronage in the history of Turkish music. In addition, the musicians people or groups who undertook the benefit of this application, what kind of benefit from this phenomenon of the artist benefiting from the patronage of this phenomenon, the patronage-artist relationship in the name of these practices made on behalf of the patronage of musicians practices in the process of professionalization of the process of
\end{abstract}

Özet

$\mathrm{Bu}$ araştırma, genel anlamda Türk müzik kültüründe sanat hamiliği ve sanatçı patronaj1 üzerine odaklanmakta ve özelde ise Türk müziği tarihi içerisindeki gerek kamusal anlamda gerekse kamusal alan dışından musikişinaslar için uygulanan himaye konusu ile ilgili Osmanlı arşiv evraklarının genel bir değerlendirmesini ortaya koymaya çalışmaktadır.

Türk tarihi içerisinde müzik sanatının gelişiminde büyük öneme haiz olan patronaj konusu araştırma kapsamında ele alınmış ve patronaj uygulamasının müzik tarihi içerisindeki yansıması ile ilgili arşiv evrakları bir araya toparlanmıştur. $\mathrm{Bu}$ evraklar esas alınarak; öncelikli olarak Türk müziği tarihi içerisindeki patronaj kapsamında hangi uygulamaların yapıldığ1 konusu aydınlatılmaya çalışılmıştır. Ayrıca musikişinas hamiliği üstlenen kişi veya guruplarn bu uygulamadan ne türlü bir fayda sağladığı, patronaj olgusundan faydalanan sanatçının bu olgudan hangi yönlü maddi veya manevi kazanım elde ettiği, hamilik adına yapilan bu uygulamalarda hami-sanatçı ilişkisinin ne şekilde yürüdüğü, musikişinas

\footnotetext{
${ }^{1}$ Bu makale, Atatürk Üniversitesi Bilimsel Araştırma Projeleri (BAP) Koordinasyon Birimi tarafından desteklenen SBA2018-6795 no’lu ve Türk Müzik Kültüründe Patronaj ve Musikişinas Hamiliği Üzerine İnceleme adlı projeden üretilmiştir. 2 Assoc. Prof. Dr., Atatürk University, KKEF Fine Arts Department, ahmet.feyzi@atauni.edu.tr (iD Orcid ID: 00000001-6455-6081

${ }_{3}^{3}$ Assoc. Prof. Dr., Atatürk University, Fine Arts Faculty, htsumbullu@atauni.edu.tr ID Orcid ID: 0000-0001-7837-7295 
Feyzi, A., \& Sümbüllü, H. T. (2019). Patronaj ve müzik ilişkisi açısından Osmanlı arşiv belgeleri üzerine bir durum değerlendirmesi. Journal of Human Sciences, 16(4), 1038-1050. doi:10.14687/jhs.v16i4.5882

professionalization and how it affected socioeconomic aspects of the related musicians thanks to the practices made, how the practices related to the patronage of musicians made during the Ottoman period were transferred to the Republican period, and to what extent the patronage was reflected in the Ottoman written literature.

Keywords: Music, patronage, archive documents.

(Extended English summary is at the end of this document) hamiliği kapsamında yapılan uygulamaların meslekleşme sürecini ne şekilde etkilediği, yapılan uygulamalar sayesinde ilgili musikişinaslann sosyoekonomik yönden nasıl etkilediği, Osmanlı döneminde yapılan musikişinas patronajına ilişkin uygulamaların Cumhuriyet dönemine ne şekilde aktarıldığı, patronaj konusunun Osmanlı yazilı yayın literatürüne ne derecede yansıdığı konuları hakkında ise genel bir durum değerlendirmesi yapılmıştır.

Anahtar Kelimeler: Müzik, patronaj, arşiv belgeleri.

\section{Giriş}

Patronaj uygulaması birçok bilim alanının ortak bir olgusu olmakla birlikte genellikle kültür ve sanat alanında aktif olarak kullanılan bir emek bedellendirme yöntemidir. Bundan dolayıdır ki kültür-sanat tarihi anlatımlarında ve özellikle bu iki alanın gelişim tarihine ait betimlemelerde üzerinde hassasiyetle durulması gereken konuların başında yer alır. Tarihsel süreç içerisinde hemen hemen tüm medeniyetlerde kültür ve sanatın en büyük destek kaynaklarından birisi olan bu uygulamanın yazılı yayın literatürüne yansıyan tarafı da yine bu anlamda dikkate değerdir. Konu ile ilgili yapılan yayınlar ilgili uygulamanın tür ve sonuçlarını ortaya koymak adına önem taşımaktadır. Çünkü kültür ve sanat politikası belirleme süreçlerinde bu uygulama ve sonuç ilişkileri ele alınmakta ve yapılacak yeni düzenleme ve belirlenecek politikalar da büyük ölçüde bu veriler üzerine inşa edilmektedir. Fakat bu yönde yapılan literatür tarama sonuçları; konunun Batı literatüründe genişçe ele alındığı fakat Türk yayın literatüründe çok fazla irdelenmediğini ortaya koymaktadır.

Batı toplumlarında patronaj ve hamilik geleneğinin kökleri Roma imparatorluğu dönemine kadar uzanmaktadır. Özellikle orta çağa kadar Batı toplumunda sanatın gelişimi ve sanatçının yaşamsal faaliyetlerini sürdürmesindeki temel itici unsur patronaj olgusu olmuştur. Bu olgu, Batı toplumunda orta çağ sonlarına kadar büyük ölçüde kilise ve aristokratlar tarafindan üstlenilmiştir. Orta çağ sonrası Rönesans dönemi sanatının gelişiminde de büyük ölçüde patronaj ve hamilik etkin olmuş sanayi, devriminin yapılışına kadar da bu etkiyi sürdürmüştür. Nitekim bu yönlü yapılan yayın çalışmaları da aynı genellemeyi doğrular niteliktedir.

Barber'in (1963) "Some Problems in the Sociology of the Professions" ve Freidson'un (1986) "Professional Powers-A Study of Institutionalization of Formal Knowledge" adlı yayınlarında meslekler sosyolojisi ile ilgili konular ele alınmış ve profesyonelleşme sürecini etkileyen hamilik olgusuna değinilmiştir. Fakat çalş̧malar farklı medeniyetlerdeki sanat gelişiminde ve bu sanat dallarının profesyonelleşme sürecinde hamilik olgusunun etkisini yeteri kadar ele almamıstır. Patronaj konusu üzerine eğilen diğer bir çalışma ise Mauss'a (2005) ait “Bağış (Hediye) Üzzerine Bir DenemeArkaik Toplumlarda Mübadele Biçimi ve Nedenleri”" adlı eserdir. Bu eser patronaj ve hediyelendirme olgusunun ortaya çıkışını ele almakla birlikte, bu olgunun gelişim ve değişimi üzerine odaklanmaktadır. Fakat genelde sanat özelde de müzik sanatının gelişiminde yaptığı etki eserde fazlaca ele alınmamaktadır. Aynı doğrultuda Brower, ve Miner'e (1988) ait "Japanese Court Poetry", adlı eserde ise Japon imparatorluğunda şiir sanatının gelişiminde patronaj etkisi ele alınmış fakat patronajın müzik sanatının gelişimine etkileri değinilmemiştir. Bu kapsamda yapılan diğer iki çalışma da Burner’a (1989) ait olan "A Study of Literary Coteries and Patronage in Seventeeth Century England" ve Griffin'e (1996) ait olan "Literary Patronage in England 1650-1800" adlı eserlerdir. Bu eserlerde 19. 
Feyzi, A., \& Sümbüllü, H. T. (2019). Patronaj ve müzik ilișkisi açısından Osmanlı arșiv belgeleri üzerine bir durum değerlendirmesi. Journal of Human Sciences, 16(4), 1038-1050. doi:10.14687/jhs.v16i4.5882

yüzyıl İngiltere’sinde sanatçılar ve patronaj konusu işlenmiştir. Bu eserler çoğunlukla edebi alanda hizmet veren sanatçılara uygulanan patronaja odaklanmış diğer ilgili eserlerde olduğu gibi özelde musikişinas himayesi fazlaca ele alınmamıştır. Musikişinas hamiliği üzerine odaklanan nadir eserlerden birisi, Kaleva'ya (2012) ait olan "Patronage Through Dissemination: Louise Hanson-Dyer's Patronage of Gustav Holst” adlı çalışmadır. Bu araştırma Avrupa'da müzik sanatının gelişiminde varlıklı ailelerin üstlenmiş olduğu hamilik üzerine eğilmektedir. Besteci ve icracıların yaşam standartlarını belirlemede önemli bir etken olan patronajın müzik sanatına etkisi eser içerisinde örnekler üzerinden irdelenmektedir ki Türk müzik kültüründe aynı yönlü yapılan çalışma örneğine pek rastlanmamaktadır. Bu kapsamda örnek gösterilecek başka yayınlarda bulunmaktadır. Fakat bu çalışmaların tamamına yakını Avrupa'daki sanatın ve özelde müziğin gelişimi üzerine odaklandığından Türk müzik kültürü ve Osmanlı dönemi musikişinas hamiliği anlamında fazla bir bilgi barındırmamaktadır.

Patronaj ve hamilik olgularının İslam toplumundaki kökleri ise $\mathrm{Hz}$. Muhammed (sav) dönemine kadar götürülebilmektedir. Hatta bu olgulara dair ilk uygulamalardan birisi olarak Hz. Muhammed (sav)'in dönem şairlerinden birisine teşvik için hırkasının hediye etmesi olayı ele alınmaktadır. Arap dünyasında Abbasi ve Emeviler döneminde de süregelen hamilik ve patronaj uygulamasının bolca örneklerine rastlanmakla birlikte 10. ve 11. yüzyılla birlikte Türklerle müşterek bir medeniyet dairesi kurdukları ve bu medeniyet dairesi içerisinde patronaj ve hamilik olgusunun büyük öneme haiz olduğuna dair bilgiler bulunmaktadır. Orta Asya ve Arap yarımadasında gitgide somutlaşan patronaj geleneğinin, Türklerin İslamiyet’i kabulü ile birlikte daha da belirginleștiği ve Türkler yoluyla Anadolu'ya taşındığına dair bulgulara rastlanmaktadır ki bu bulgular geleneğin Selçuklulardan Osmanlı beyliğine intikal ettiğini ortaya koymaktadır. Türk müzik kültüründe patronaj uygulamasının kökenleri ise ilk Türk devletlerine kadar uzanmaktadır ki bu anlamda örnek olarak verilmesi gerekenler halk ozanlarıdır. İlk Türk devletlerinde hanedanlık tarafından koruma altına alınan ve sarayda han sarayında ikamet ettirilerek sarayı topluma tanitan bu ozanlar saray ve han patronajından faydalanmışlardır.

Türklerin İslamiyet'i kabulü ile birlikte Asya'dan Anadolu'ya yayılan Türklerle birlikte, sahip oldukları kültürel birikimde bu topraklara taşınmıştır. Müşterek İslam medeniyetinin bir parçası olan Türk kültürü içerisinde iyiden iyiye varlığını gösteren patronaj kültürel alanların tümünde olduğu gibi müzik kültüründe de değişik şekillerde kendini göstermeye başlamıştur. Patronaj sistemi, Türk kültürü içerisinde siyasetnâme ve nasihatnâmelerle eğitim tamamlayan hükümdar namzetleri vasitasıyla ricâli devlet ve ekâbir zümresi tarafindan benimsenmiş ve sistem zamanla sanatçı-patron çerçevesinde şekillenen bir mübadele şeklini almıştır. Patronaj ve hamilik geleneğinin en önemli yürütücüsü ise Osmanlı hanedan ailesidir. İmparatorluğun temellerinin atılmasının ardından tahta geçen bütün padişahların bu anlamda cömert ve istekli davrandıklarına dair birçok arşiv belgesi örneğine rastlanmaktadır.

Hamilik konusunda Türkiye'de yapılan yayınlara bakıldığında yayınların büyük bir çoğunluğunun edebi alanla ilgili olduğu görülmektedir. Bu bağlamda dikkate değer bir eser Durmuş (2009) tarafindan yapılan "Tutsan Elini Ben Fakîrin-Osmanlı Edebiyatında Hamilik Geleneği”" adlı kitap çalışmasıdır. Bu çalışmada Durmuş, Osmanlı edebiyatının gelişiminde hamilik geleneğinin yapmış olduğu etkiyi ele almış şairler ve bu şairlerin patronaj kapsamında sağladığı maddi ve manevi olanakları ortaya koymaya çalışmıştur. Eserde müzik sanatı ile ilgili herhangi bir konuya değinilmemiştir. Bu kapsamda yapılan diğer ilgi çekici bir çalışma ise Erdoğan (2013) tarafindan yapılan "Yurtdışı Eğitimi ve Türk Modernleşmesi” doktora tezidir. Bu tez, hamilik geleneğinin ilginç bir aracı olan yurtdışına öğrenci gönderme olgusu üzerine odaklanmasına rağmen eğitim için yurtdısına gönderilen musikişinaslar özelde ele alınmamıştır. Fakat bu konuda Feyzi (2016) tarafindan yapılan "Türk Müzik Kültüründe bir Patronaj Aracının Kökeni Üzerine İnceleme-"Mûsıkî Tahsili İçin Avrupa'ya Öğrenci Gönderme”, adlı çalışma, bu yönlü yayın alanına katkı sağlamayı amaç edinmiş müzik sanatı hamiliğini ele alan bir çalışmadır. Çalışmada yurtdışına musiki tahsili için gönderilen öğrenciler ele alınmış ve bu öğrencilerin Türk müzik kültürüne sağladıkları katkılar incelenmiştir. Yine Feyzi ve Özden (2016) tarafindan yapılan "Müzik Kültüründe Patrimonyal sistem 
Feyzi, A., \& Sümbüllü, H. T. (2019). Patronaj ve müzik ilișkisi açısından Osmanlı arșiv belgeleri üzerine bir durum değerlendirmesi. Journal of Human Sciences, 16(4), 1038-1050. doi:10.14687/jhs.v16i4.5882

ve On dokuzuncu Yüzyılla Birlikte Gelen Değişim” adlı araştırmada musiki sanatında hamilik konusunu ele alan yayınlardan birisidir ki bu yayın hamilik araçlarından birisi olan nişan ve madalya sunma geleneğini müstakil olarak ele almış fakat patronaj olgusunun müzik kültürü üzerine diğer yansımalarını araştırma kapsamı dışında bırakmıştır. Hamilik konusunda ülkemizde yapılan en önemli çalışmaların başında İnalcık (2015) tarafindan yapılan "Şair ve Patron-Patrimonyal Devlet ve Sanat Üzerinde Sosyolojik Bir İnceleme” adlı eser gelmektedir. Bu eser genel anlamda patronaj konusunu ele alarak özelde himaye edilen şairler ve şiir sanatının Osmanlı'daki gelişiminde patronajın etkisi konusuna odaklanmaktadır. Bu çalışmada Osmanlı'da musikişinas hamiliği üzerine kısmi bilgiler bulunsa da asıl itibariyle patronajın edebi alana yansımaları detaylarıla ele alınmıstır. Bu kapsamda yapılan diğer bir çalışma ise Tatlısumak (2016) tarafindan yapılan "Osmanlı Ulemâsı ve Patronaj İlişkisi” adlı doktora tezidir. Bu tez patronaj olgusunun Osmanlı uleması üzerinde yapmış olduğu etki ve hanedan ulema ilişkilerinin patronaj bağlamında irdelenmesi konusuna odaklanmış, patronaj konusunun diğer bilim ve sanat alanlarıyla olan ilişkisi fazlaca ele alınmamıștır.

Alan yazın özetinden de anlaşılacağı üzere patronaj konusu, müzik alanına yönelik yeteri derecede ele alınmamıştır. Bu eksikliğin ise özellikle tarihsel müzikolojiye yönelik eğitim-öğretim materyali açısından bazı aksamalara neden sebebiyet verdiği düşünülmektedir. Özellikle Osmanlı dönemi Türk müziği tarihi anlatımlanında imparatorluk bürokrasisi tarafindan benimsenen müzik politikasının ne şekilde hayatiyet bulduğu ve nasıl bir uygulama yapıldığı konusu kısmi olarak karanlıkta kalmaktadır. Ayrıca bu konu ile ilgili arşiv belgelerinin mahiyetinin ne olduğu konusu da henüz netlik kazanmamıştur.

Yapılan bu araştırmada, Osmanlı arşiv belgeleri tasnif edilerek elde edilen sonuçlar ile bu karanlık alanı kısmi de olsa aydınlatmak, patronaj uygulamasının Osmanlı devletinin kuruluşundan günümüze kadar müzik sanatına nasıl yansıdığını ortaya koymak ve eğitim-öğretim sürecinde örnek olarak gösterilecek kanıtlara katkı sağlama amaçlanmıştır.

\section{Yöntem}

Bu araştırma, yapı itibari ile nitel bir araştırmadır. Araştırmanın yürütülmesinde ise "var olan kayıt ve belgeleri inceleyerek veri toplama" (Karasar, 2013: 183) olarak tanımlanan olan belgesel tarama modeli kullanılmıştır. Tarihsel araşturmalarda sıklıkla kullanılan bu modelin temel gereksinimleri veri bulma ve kontrol güçlügüdür. Araştırmada bu gereksinimlerin karşılanması adına tarihsel araştırmalarda kullanılan en geçerli bilgi kaynağı olan arşiv belgeleri esas alınmıştır. Bu evrak türlerinin araştırmada esas alınma nedeni ise tarihsel araştırmaların, öncelikli olarak yazılı resmi evraklara dayalı olarak yapılma zorunluluğudur. Bu bağlamda araştırma konusu olan Osmanlı dönemi müzik kültüründe patronaj ile ilgili belge ve resmi evraklar ilgili arşiv, kütüphane ve müzelerden tarama yöntemi ile elde edilmiştir. Araştırmaya katkı sağlayacak nitelikte toparlanmış olan evrak türlerinin tamamen resmi evrak niteliği taşıması, araştırma sonucunda elde edilen bilgilerin de güvenilir olmasını beraberinde getirmiştir.

Araştırma sürecinde elde edilen arşiv belgeleri "Yazll, görsel malzemenin toplanıp incelenmesi” (Sönmez ve Alacapınar, 2011: 83) olarak tanımlanan doküman inceleme tekniğiyle ele alınmış ve tahlil edilmiştir. Elde edilen bu belgeler, transkripsiyonun ardından tasnif, tahlil ve tenkit işlemine tabi tutularak konuyla ilgili olan evraklar bir veri havuzunda toparlanmıştır. Yapılan analiz işleminin ardından, elde edilen verilerden yola çıkılarak Osmanlı arşivlerindeki ilgili evraklar ışı̆̆ında; Osmanlı dönemi müzik politikalarında önemli bir yeri olan patronaj uygulamasının türleri, uygulanma şekli, araçlanı, kimlere uygulandığı ve patronajın iki tarafı olan hami ve sanatçının bu olgudan elde ettiği maddi ve manevi kazanımların neler olduğu, patronaj uygulamasını iyi ve kötü tarafları tespit edilmeye çalışılmıştır. 
Feyzi, A., \& Sümbüllü, H. T. (2019). Patronaj ve müzik ilișkisi açısından Osmanlı arșiv belgeleri üzerine bir durum değerlendirmesi. Journal of Human Sciences, 16(4), 1038-1050. doi:10.14687/jhs.v16i4.5882

\section{Bulgular}

Araştırmadan elde edilen arşiv belgeleri ve yapılan literatür taraması bazı betimlemeleri yapmayı mümkün kılmıştır ki bu kaynaklardan yola çıkarak Türk müziği tarihi içerisinde patronaj olgusunun müzik sanatının gelişiminde önemli derecede itici bir güç olduğu anlaşılmıştır. Konu daha da detaylandırıldığında ise bu olgunun değişik şekillerde Türk müziği tarihine etki ettiği ve patronaj uygulamasının farklı araçlarla somutlaştı̆̆ı görülmüştür.

Araştırmada elde edilen arşiv evraklarından yola çıkılarak patronaj ve müzik ilişkisine yönelik tarihsel süreç betimlenmiş ve somutlaşturlmıştır.

\section{Kuruluştan Tanzimat'a Türk Müzik Kültüründe Patronaj \\ - Türk Müzik Kültüründe Yazılı Yayın Geleneği ve Patronaj \\ - Osmanlı Müzik Kurumları ve Patronaj \\ Mebterbâne-i Tabl ü Allem Enderuin}

\section{Tanzimat'tan Cumhuriyet'e Türk Müzik Kültüründe Patronaj}

- Gösteri Sanatlarının Himayesi

- Nişan ve Madalya Sunma Geleneği

- Musika-i Hümayun ve Patronaj

- Padişah huzurunda Yapılan Gösteriler ve Hediyelendirme

- Marş ve eser ithafi

- Yurtdışına Öğrenci Gönderme

- Yabancı Sanat Kurumları ve Yerli-Yabancı Mûsıkisşinas Taltifleri

Türk müzik kültüründe 19. yüzyıl tarihsel bir eksen olarak ele alındığında 19. yüzyıl öncesinde patronaj uygulamalarının ilk belirtileri yayım patronajı ile görülmeye başlamıştır. Türk müzik kültüründe edvar ve risale yazma geleneği ise patronaj konusunun yansımalarını taşıyan önemli yazılı yayın literatürüdür ki bu edvar ve risalelerin ortaya çıkışında en önemli faktör hami teşviğidir. $\mathrm{Bu}$ teşvik sonucunda birçok edvar yazılmış ve bu edvarlar teşvik edici konumunda bulunan hükümdarlar tarafından maddi-manevi olarak hediyelendirilmiştir. Konu ile ilgili bir örnek, Yapı Kredi bankası arşivinde bulunan edvardaki şu ifadelerdir:

\section{Fe innî eredtü en ellefe külli' i-külliyât ve büve mecmau'l-makâmâti ve'l-âvâzâti ve şu'ubâti ve't-terâkî̉bi li-eclil sultânüll-berri ve'l-bahreyn fâthüll-Misır ve hâfizul-Harameyn min Rabbi'l-âlemîn a'nî es-Sultân İbn-i Sultân, Sultan Selim Hân ve şerâtubu ve kasadtu ilâ itmâmibi hatta yekûnu eseren minni ilâ yevmi'l-keryâmeti ve kesertubu elâ erbaâti akfâl (Tekin, 2003: 51-52).}

Yazarın, Yavuz Sultan Selim Han hakkında kullandığı methiyelerinden bir hami olarak hükümdarı gördüğü ve hükümdarla yakınlık kurmak ve destek almak amacında olduğunu anlamak pek zor değildir. Bu durumun yayın patronajı açısından sarayın ne derece önem taşıdığına örnek teşkil ettiği düşünülmektedir.

Türk müzik kültüründe patronaj konusunun işlenişinde ele alınması gereken diğer hususlar tarih içerisinde var olan kurumsal yapılar ve bu yapılar içerisindeki patronaj olgusunun konumudur. Bu kurumsal yapıların ilki olan Mehterhane-i Tabl ü Âlem, Türk müzik kültürünün ilk profesyonel nitelikteki müzik kuruluşu olması nedeniyle sabit ücretlendirmeli ve tam zamanlı eleman istihdamı yapılan teşekkülüdür. Fakat bu durum Mehterhane içerisinde taltifat örneklerinin ortaya çıkmasına engel teşkil etmemiştir. Toplumsal açıdan önem taşıyan tören ve teşrîfâtlarda Mehterhane içerinde görevli çalıcı mehterler sabit ücretlendirmeleri yani ulufeleri dışında maddi ve manevi olarak taltif edilmişlerdir. 
Feyzi, A., \& Sümbüllü, H. T. (2019). Patronaj ve müzik ilişkisi açısından Osmanlı arşiv belgeleri üzerine bir durum değerlendirmesi. Journal of Human Sciences, 16(4), 1038-1050. doi:10.14687/jhs.v16i4.5882

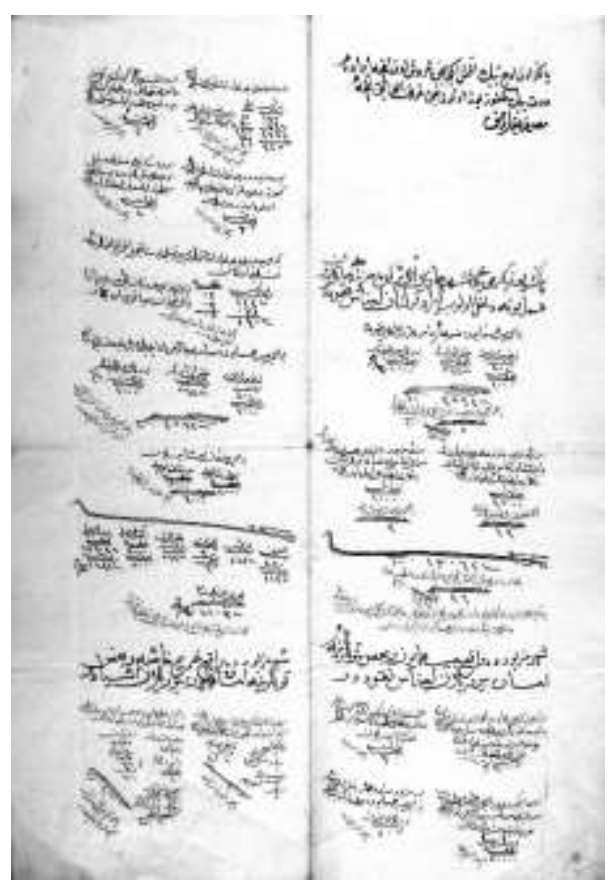

Görsel 1: Mehterhane-i Tabl ü Âlem’e Yönelik Vesika Örneği (BOA-D 2358/5)

Görsel 1'de Mehterhane-i Tabl ü Âlem'e yönelik BOA-D 2358/5 no'lu bir vesika örneği görülmektedir. Bu vesikada, 1127 Senesine ait Ceyb-i Hümâyûn ve Harc-1 Hâssa Defterinden Mehterbaşı ve Neferlerine ihsan olunan bahşişler kaydedilmiştir.

Türk müzik kültüründe önem arz eden ve patronaj olgusunun ciddi şekilde işleyiş kazandığ1 diğer bir kurumsal yap1 Enderûn mektebidir ki saray okulu olan bu kurum bir nevi özel okul satatüsü taşımaktadır. Üst düzey eğitim olanağının sağlandığı bu kurumda görev alan mûsıkîşinaslar da zamanının en gözdeleri olan ve sarayda ders verme ayrıcalığı kazanan kişilerdir ki bu kişilerin saraya alınması kendilerine verilen lütufların en büyüğüdür. Özellikle 18. yüzyllla birlikte mûsıkî yeteneğine sahip olan gençler Enderûn'a kabul edilip burada görevlendirilerek belki de en önemli hamilik uygulamalarıyla karşılaşmışlardır.

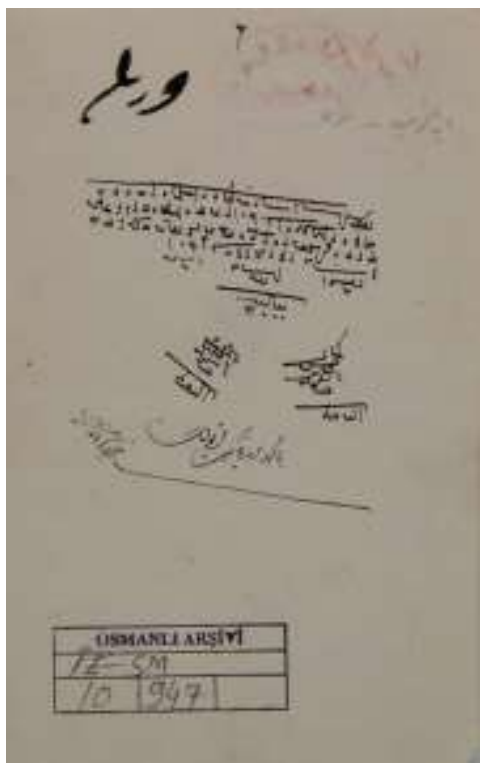

Görsel 2: Enderûn Mektebi’ne Yönelik Vesika Örneği (BOA-İE.SM 10/947) 
Feyzi, A., \& Sümbüllü, H. T. (2019). Patronaj ve müzik ilişkisi açısından Osmanlı arşiv belgeleri üzerine bir durum değerlendirmesi. Journal of Human Sciences, 16(4), 1038-1050. doi:10.14687/jhs.v16i4.5882

Görsel 2'de Enderûn Mektebi'ne yönelik BOA-İE.SM 10/947 no’lu bir vesika örneği görülmektedir. Bu vesikada, Enderûn-i Hümâyûn Muallimi Kemani Hasan ve Neyzen Mehmed Çelebi'nin Nafaka Bahalarını Mübeyyin Makbuz kaydedilmiştir.

Tanzimat döneminin başlangıcıyla hayatiyet bulan Musika-i Hümâyûn, Türk müzik kültürünün en büyük değişimlerinden birisi olmasının yanı sıra patronaj sistemine dair uygulamaların Mehterhaneden sonra izlenebildiği ve bu uygulamalardaki değişimlerin net bir şekilde izlenebildiği en önemli kurumsal yapısıdır. Yüzyıl içerisindeki patronaj kapsamındaki en önemli maddi ve manevi hediyelendirmeler bu kurum içerisinde yapılmıştır. Bu kurum içerisinde görev alan personele ödenen sabit gelir haricinde, hanedan ailesinin kurum personeline yapmş olduğu taltîfât ve hediyeler yüzlerce arşiv belgesine konu olmuştur.

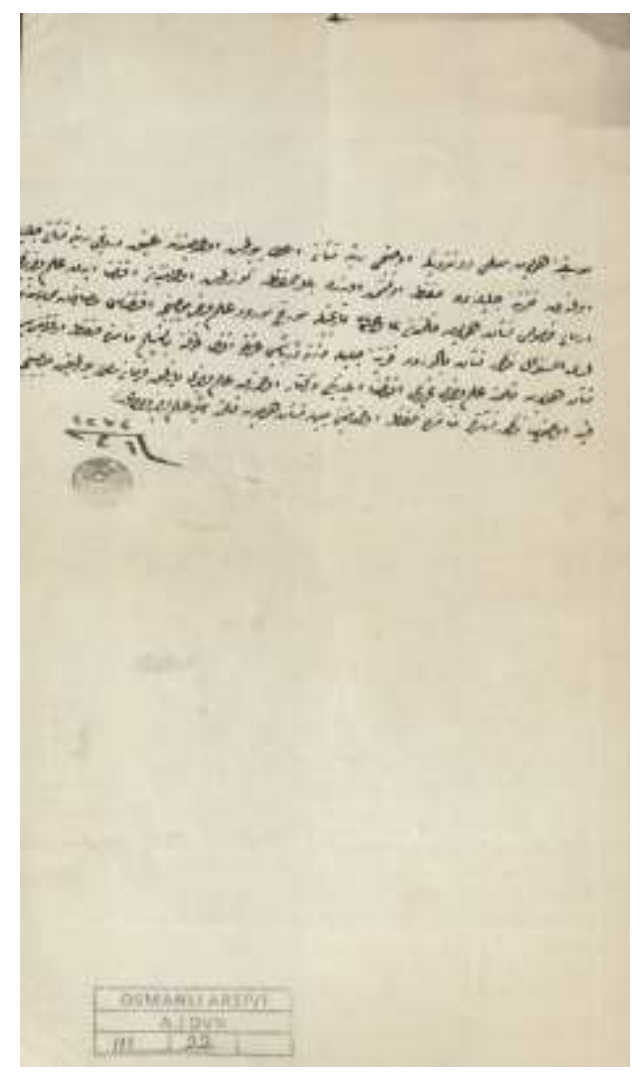

Görsel 3: Musika-i Hümayun’a Yönelik Vesika Örneği (BOA.A-DVN 111/22)

Görsel 3'de Musika-i Hümayun'a yönelik BOA.A-DVN 111/22 no'lu bir vesika örneği görülmektedir. Bu vesikada, Musika-i Hümayun Muallimi Donizetti Bey'e Üçüncü Rütbe'den Nişan Tevcihinden bahsedilmektedir.

Türk müziği kültürü içerisinde 19. yüzyılla birlikte ortaya çıkan başka bir olgu ise marş besteleme ve hanedan üyelerine ithaf etme olgusudur ki bu yolla Türk müzik kültürü hem yeni bir müzikal formla tanışmış hem de patronaj sistemi hediyelendirmeye araç olacak yepyeni bir davranış şeklini bünyesine dahil etmiştir. 
Feyzi, A., \& Sümbüllü, H. T. (2019). Patronaj ve müzik ilişkisi açısından Osmanlı arşiv belgeleri üzerine bir durum değerlendirmesi. Journal of Human Sciences, 16(4), 1038-1050. doi:10.14687/jhs.v16i4.5882

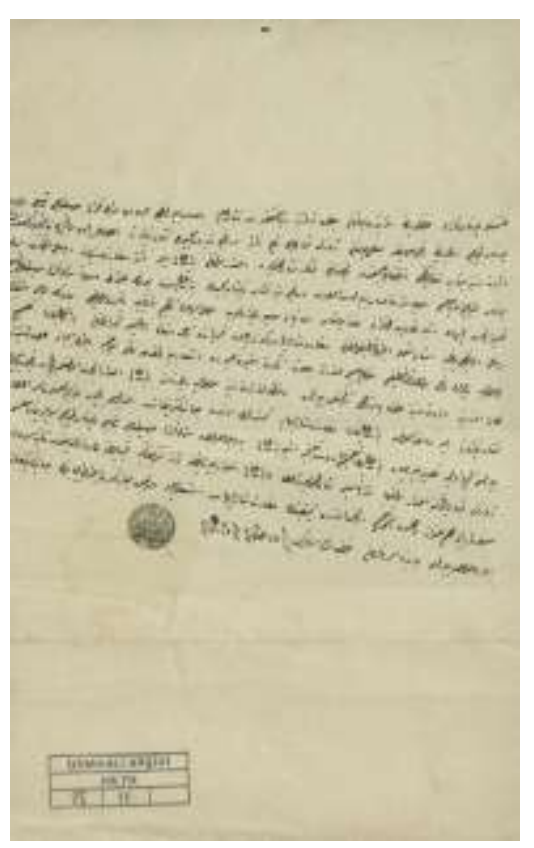

Görsel 4: Marş Bestelemeye Yönelik Vesika Örneği (BOA-HR.TH 88/11)

Görsel 4'de Marş bestelemeye yönelik BOA-HR.TH 88/11 no'lu bir vesika örneği görülmektedir. Bu vesikada, Padişaha Marş Tertip Eden Almanyalı Mösyö Sayler'e Dördüncü Rütbeden Mecidi Nisanı ve Beratının gönderilmesinden bahsedilmektedir.

Tanzimat dönemi öncesinde başlayan eğitim alanındaki yenileşme bu dönemle birlikte devam etmiş bu değişim yepyeni bir patronaj aracının temelini oluşumunu da beraberinde getirmiştir. Yurtdışına eğitim için öğrenci gönderme şeklinde somutlaşan bu durum ilerleyen yllarla birlikte bir devlet patronajı kimliğine bürünmüştür ki bu imkandan faydalanan birçok mûsıkisşinas Türk müzik kültürünün önemli isimleri arasında yer almıştır.

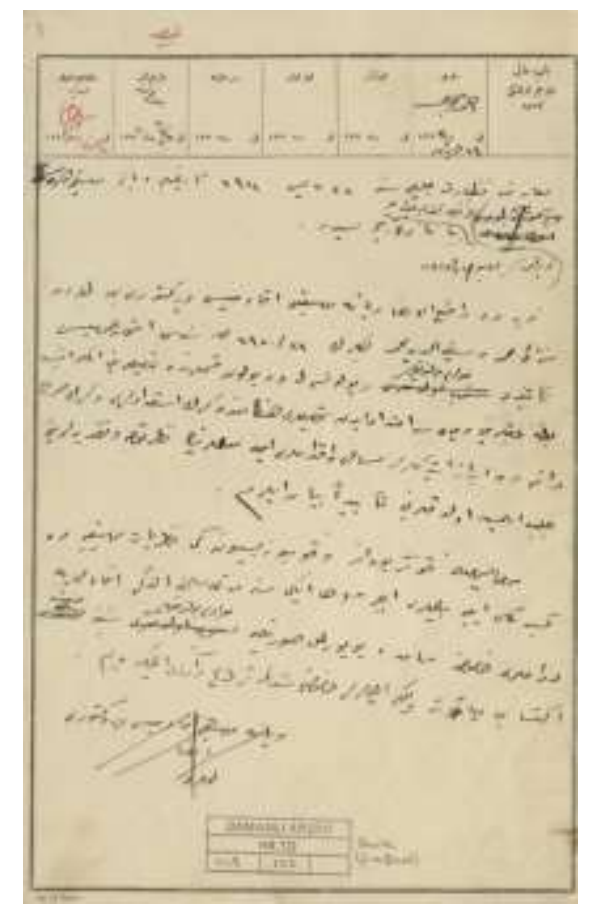

Görsel 5: Yurt Dışına Öğrenci Göndermeye Yönelik Vesika Örneği (BOA-HR.TO 548/122) 
Feyzi, A., \& Sümbüllü, H. T. (2019). Patronaj ve müzik ilișkisi açısından Osmanlı arșiv belgeleri üzerine bir durum değerlendirmesi. Journal of Human Sciences, 16(4), 1038-1050. doi:10.14687/jhs.v16i4.5882

Görsel 5'de yurt dişına öğrenci göndermeye yönelik BOA-HR.TO 548/122 no’lu bir vesika örneği görülmektedir. Bu vesikada, yedi seneden beri musiki tahsiline devam eden Sezai Mehmed ve Seyfettin Mehmed beylerin istidalı olup iki yıl daha devamları hususunda Viyana Musiki Akademisi Direktörü Mösyö Love tarafindan padişaha gönderilen arizadan bahsetmektedir.

Osmanlı hanedanının hamilik, taltif ve hediyelendirme bağlamında hemen hemen her dönemde fazlasıyla cömert davrandığını söylemek mümkündür. Arşivlerde yer edinen konu ile ilgili birçok belge de bu durumun somut kanıtları arasındadır. Durumu örnekleme adına incelenen evrakların büyük çoğunluğunun 19. yüzyıl ve sonrasına ait olması bu yüzyılda hanedanın sanat patronajı anlayışını ortaya koymakta ve bazı tespitler yapmayı mümkün kılmaktadır. Bu tespitlerden ilki bu yüzyıl içerisindeki hediyelendirme ve taltifâtların geçmiş yüzyıllara nazaran daha yoğun olduğudur.

Osmanlı döneminden sonra yeni kurulan Türkiye Cumhuriyeti de bu hediyelendirme ve taltifatları devam ettirdiği görülmektedir. Fakat bu hediyelendirme ve taltifatlar yurtdışına eğitim için öğrenci gönderme şeklinde somutlaşan bir devlet patronajı kimliğine büründüğü söylenebilir.

\section{Sonuçlar}

Araştırmada elde edilen bulgular doğrultusunda Osmanlı devletinin kuruluşundan Cumhuriyet dönemine kadar olan dönem içerisinde her ne kadar yazılı olmasa da müzik kültürünün geliştirmesine yönelik bazı temayüller belirlenmiştir. Bu temayüllerin en önemlisi patronaj ve hamiliktir. Bu olgular Türk müzik kültürünün gelişiminde en önemli itici güçlerden birisi olmuştur. Maddi ve manevi olarak saraya tarafindan himaye edilen, desteklenen sanatçlar Türk müzik kültürünün gelişiminde önemli bir yer edinmiş ve bu yolla önemli ölçüde eser üretimi sağlanmıştır. Başka bir açıdan bakıldığında ise hamilik ve patronajın Osmanlı döneminin en büyük kültür politikalarından birisi olduğunu söylemek mümkündür. Anadolu toprakları uygulanan bu politika neticesinde tarihin her döneminde ilim ve sanat merkezi olarak işlevselleşmiştir.

Araştırma kapsamında inceleme alına alınan arşiv belgeleri bu politikanın yazılı kayıtlarıdır. Araştırmadan elde edilen sonuçlar şöyle sıralanabilir.

1. Patronaj konusunda yapılan arşiv taramasında birçok yazılı resmi evrak örneğine rastlanmıştır. Bu arşiv evraklarının bir kısmı doğrudan konuyla ilgili olmakla birlikte diğer bir kısmı dolaylı olarak Osmanlı dönemi müzik sanatı patronajına katkı sağlamaktadır. Bu evrakların çok büyük bir kısmı 19. yüzyıl sonrasına dair uygulamaları belgelemektedir. İlgili arşiv evraklarının bir kısmına ait künye bilgileri ise şu şekildedir:

- BOA-A\}AMD: 11/29, 24/59

- BOA-A\}DVN: 111/22, 131/33

- BOA-A \}MKT: 189/74, 45/53, 257/19, 56/69, 52/16, 128/6

- BOA-A\}MKT.MHM: 423/78, 243/68, 390/80, 111/62

- BOA-A\} MKT. MVL: 37/82, 70/85

- BOA-A\} MKT. NZD: 78/14, 2/73

- BOA-BEO: 1465/109837, 48/3586, 278/20814, 298/22314, 3627/271956, 4416/331142, 4400/329989, 4417/331259, 4420/331488, 4438/332784, 296/22184, 67/5010, 3669/275145, 3547/268017, 4128/309592, 1900/142483, 5/364, 142/10631, 670/50213, 2737/205265, 571/42768, 2449/183605, 182/13616

- BOA-C.AS: 1206/54032, 183/7936, 899/38695

- BOA-C.BH: $17 / 827$

- BOA-C.BLD: $13 / 648$

- BOA-C.EV: 562/28368, 223/1111

- BOA-C.DH: 27/1305 
Feyzi, A., \& Sümbüllü, H. T. (2019). Patronaj ve müzik ilişkisi açısından Osmanlı arşiv belgeleri üzerine bir durum değerlendirmesi. Journal of Human Sciences, 16(4), 1038-1050. doi:10.14687/jhs.v16i4.5882

- BOA-C.SM: 85/4272, 19/973, 127/6379, 147/7373, 98/4925, 103/5168, 18/903, 30/1519

- BOA-D.BŞM.d: 42566, 6263, 3065, 2991, 2519,

- BOA-DH.EUM.1.Şb: 8/35

- BOA-DH.EUM. 3.Şb: 26/21, 23/46

- BOA-DH.EUM.SSM: 59/51, 59/31

- BOA-DH.İ.UM: 94/5

- BOA-DH.MKT: 1586/19, 2646/85

- BOA-HR.TO: $12 / 7,348 / 83,73 / 9,501 / 23,107 / 79$

- BOA-HH.MH: 611/17

- BOA-İ.DH: 519/35330, 1256/98569, 305/19366, 535/37159, 974/76931, 1217/95349, 1237/96872, 588/40919, 388/25625, 942/74616

- BOA-İ.DUIT: 17/35, 12/64, 12/109, 16/89, 16/90, 16/98, 12/68, 12/70, 16/85, 16/89, 16/90, 16/91, 16/95, 17/8, 17/22, 17/30

- BOA-İ.HR: 291/18315, 24/1121, 12/609, 304/19308, 145/7659, 150/7895, 4/198, 190/18235, 290/18235, 263/15771, 97/4751, 41/1915, 228/13400, 266/15942, 287/17967, 46/2198, 180/10010

- BOA-İ.HUS: $174 / 25,181 / 16$

- BOA-İ.TAL: 329/4, 116/60, 326/68, 351/58, 73/58, 40/44, 112/85, 80/78, 246/75, 83/91, $337 / 31,100 / 59,115 / 5,27 / 37,79 / 36,24 / 1310$

- BOA-İE.EV: $29 / 3312$

- BOA-İE.SM: 9/879, 8/794, 7/692,9/881

- BOA-MF.MKT: 1234/114, 1091/9, 1169/20, 1234/114, 1226/93, 918/11, 1226/93

- BOA-ML.MSF.d 19457

- BOA-MV: 194/32, 241/163

- BOA-ŞD: $349 / 10$

- BOA-TS.MA.d: 2352/327, 2438/203, 2439/57, 2352/303, 2352/994, 2353/457, 9623, 6494, 407, 2436

- BOA-Y.A.HUS: 319/58, 272/133

2. Türk müziği tarihi içerisinde patronaj kapsamında hangi uygulamaların yapıldığ1 belirlenmiştir. Bu uygulamalar yukarıda da liste halinde verilen temayüllerdir. Bu temayüller doğrudan olmasa da dolaylı olarak Osmanlı dönemi sanatı ve özelde müzik sanatında benimsenen politikalar olarak işlevselleşmiştir.

3. Musikişinas hamiliği üstlenen kişi veya gurupların bu uygulamadan ne türlü bir fayda sağladığı konusu açılığa kavuşturulmuştur. Bu bağlamda patronaj olgusunun ilgili hamiye meşruiyet kazandırdığı, tanınırlığna katkı sağladığı ve uluslararası anlamda hanedanlık gücünün artırılmasında büyük öneme haiz olduğu anlaşılmıştır.

4. Patronaj olgusundan faydalanan sanatçının bu olgudan hangi yönlü maddi veya manevi kazanım elde ettiğgi konusu da belgeler ışığında aydınlatılmıştır. Nitekim Türk müziği tarihi içerisinde ismine önem atfedilen besteci ve icracıların birçoğunun saray himayesinden faydalandığı veya sarayın bu tanınmış kişileri doğrudan veya dolaylı olarak himaye ettiği görülmüştür. Buna bağlı olarak ta ilgili besteci ve icracının gerek maddi gerekse manevi anlamda bu himayeden etkilendiği ve yaşam standartlarının diğer besteci ve icracıların aksine daha yüksek olduğu anlaşılmıştır.

5. Hamilik adına yapılan bu uygulamalarda hami-sanatçı ilişkisinin ne şekilde yürüdügü, konusuna bakıldığında ise iki farklı uygulamanın olduğu görülmüştür ki bunlardan ilki sanatçının saraya intisap etmesi yani hükümdar himayesi altında olmak için eserlerini kendi inisiyatifiyle saraya sunması şeklindedir. Bu ilişkinin ikinci şekli ise sarayın besteci ve icracıyı kendi isteği doğrultusunda himayesi altına alması, maddi ve manevi olarak bu besteci ve icracının eser üretimini teşvik etmesi şeklindedir. 
Feyzi, A., \& Sümbüllü, H. T. (2019). Patronaj ve müzik ilișkisi açısından Osmanlı arșiv belgeleri üzerine bir durum değerlendirmesi. Journal of Human Sciences, 16(4), 1038-1050. doi:10.14687/jhs.v16i4.5882

6. Musikişinas hamiliği kapsamında yapılan uygulamaların meslekleşme sürecini ne şekilde etkilediği konusu da bu araştırmada aydınlığa kavuşturulmuştur. Hamilik kapsamında yapılan uygulamalar musikişinaslık uğraşının bir meslek olarak görülme düzeyini toplumda artırmıştır. Toplumsal anlamda değişen bu alg1 ilgili sanat dalının eğitim ve öğretiminin gerekli olduğu gerçeğinin de toplumca kabulünü sağlamıştır. Buna bağlı olarak ise ilgili sanat dalı meslekleşme sürecinde ilerlemiş yine saray hamiliği sayesinde okullaşma ve meslekleşmeye dair uygulamaların ilkleri Osmanlı dönemi itibari ile görülmeye başlamıştır.

7. Yapılan uygulamalar sayesinde ilgili musikişinasların sosyoekonomik yönden nasıl etkilendiği konusu ise ilgili arşiv evraklarına yansıyan bir durumdur ki arşiv evraklarından da görüleceği üzere saray patronajından faydalanan besteci ve icracılar döneminin diğer mûsıkisşinaslarına nazaran daha yüksek bir sosyo-ekonomik duruma sahip olmuşlardır. Mûsıkîşinaslık uğraşının henüz meslek olarak kabul görmediği dönemlerde sarayın bu kişilere sağladığı maddi ve manevi olanaklar bu kişilerin sadece tanınırlıklarına katkı sağlamamıs bu tanınırlıklarına paralel olarak önceleri musahiplik ve nedimlik gibi görevler almışlar daha sonraki yüzyıllarda da saray içerisinde daimî görevlendirmelerle hediyelendirilmişlerdir. Bunun devamında ise çırağ edilerek emeklilik benzeri bir özlük hakkını da elde etmişlerdir. Bu görevler dışında sanat dallarıla alakasız bazı üst düzey bürokratik görevler de üstlenmişlerdir. Bundan dolayıdır ki saray himayesinden faydalanan hemen her besteci ve icracı sosyoekonomik yönden bu durumdan fayda sağlamıştır.

8. Osmanlı dönemi kültür-sanatının patronajdan ne derece etkilendiği ve patronajın olumlu ve olumsuz yönlerinin neler olduğu konusu da araştırma sürecinde elde edilen belgeler ve taranan literatürden anlaşılmıştır. Elde edilen arşiv belgelerinden anlaşıldığı kadarıyla Osmanlı dönemi sanat ve müzik politikasının temelini büyük ölçüde patronaj ve sanatçı hamiliği oluşturmaktadır. Yazılı herhangi bir nizamname veya benzeri bir belgeye bu politikanın içeriği yansımamış olsa da Osmanlı dönemi sanat ve müzik politikasının temelini himaye oluşturmaktadır. Genelde sanat adamları özelde ise besteci ve icracıların Osmanlı döneminde sabit ve tam zamanlı olarak görevlendirildiği veya benzer bir şekilde istihdam edildiği tek mecranın saray olması ve bu kişilerin saray tarafından himaye altına alınarak eser üretimine devam etmesi dönem musiki hayatını önemli ölçüde etkilemiştir. Müzik sanatında en önemli besteci ve icracılar saray tarafindan kısmen istihdam edilmiş ve bu besteci ve icracılar eser üretimleri ilgili hamiyeden büyük ölçüde etkilenmiştir.

9. Arşiv belgelerinden elde edilen bilgilerden yola çıkılarak Osmanlı döneminde yapılan musikişinas patronajının müzik sanatına büyük ölçüde etki ettiği ve bu etkinin Cumhuriyet dönemiyle birlikte sürdüğü anlaşılmaktadır. Nitekim yeni kurulan Cumhuriyet dönemi kültür sanat politikalarının Osmanlı döneminde temellerinin atıldığını söylemek yerinde olacaktır. Tanzimat döneminin ardından belirmeye başlayan Batı eğilimli sanat anlayışının Cumhuriyet döneminde de devam ettiği görülmektedir. Bu politikanın temelini Osmanlı dönemindeki saray himayesinde benimsenen temayüller oluşturmaktadır. Cumhuriyet dönemi ile birlikte aynı yönlü politikanın devam ettiği görülmektedir ki bu dönemde de aynı yönlü eğilimin devam ettiği görülmektedir. Buna paralel olarak devlet patronajının Cumhuriyet dönemine de taşındığı anlaşılmaktadır. Cumhuriyetin ilanının ardından çıkarılan ve sanat alanında yetenekli gençlere yurtdışı eğitim imkanı sağlayan yasaların çıkarılması da bu durumu somut olarak örneklemektedir.

\section{Kaynakça}

Barber, B. (1963), Some Problems in the Sociology of the Professions, Daedalus, Vol. 92, No. 4, The Professions, pp. 669-688

Brower, R.H. ve Miner, E. (1988). Japanese Court Poetry. Stanford University Press United Kindom Burner, E. S. (1989). James Shirley-A Study of Literary Coteries and Patronage in Seventeeth Century England, University Press of America: ABD

Durmuş, T. I. (2009), Tutsan Elini Ben Fakîrin-Osmanlı Edebiyatında Hamilik Geleneği, İstanbul, Doğan Yayıncılık 
Feyzi, A., \& Sümbüllü, H. T. (2019). Patronaj ve müzik ilișkisi açısından Osmanlı arșiv belgeleri üzerine bir durum değerlendirmesi. Journal of Human Sciences, 16(4), 1038-1050. doi:10.14687/jhs.v16i4.5882

Erdoğan, A. (2013), Yurtdış1 Eğitimi ve Türk Modernleşmesi, İstanbul Üniversitesi, Sosyal Bilimler Enstitüsü, Yayınlanmış Doktora Tezi

Feyzi, A. (2016),Türk Müzik Kültüründe bir Patronaj Aracının Kökeni Üzerine İnceleme- "Müzik Tahsili İçin Avrupa’ya Öğrenci Gönderme", Medeniyet Sanat, İMÜ Sanat, Tasarım ve Mimarlık Fakültesi Dergisi, Cilt:2, Sayı:2, s.47-73

Feyzi, A. ve Özden, E. (2016), Türk Müzik Kültüründe Patrimonyal sistem ve Ondokuzuncu Yüzyllla Birlikte Gelen Değişim, Uluslararası Sosyal Araşturmalar Dergisi, Cilt:9, Sayı: 47, s.1195-1209

Freidson, E. (1986), Professional Powers-A Study of Institutionalization of Formal Knowledge, Chicago and London, The University of Chicago Press

Griffin, H. D. (1996). Literary Patronage in England 1650-1800. Cambridge University Press: United Kindom

İnalcık, H. (2015). Şair ve Patron-Patrimonyal Devlet ve Sanat Üzerinde Sosyolojik Bir İnceleme, Ankara, Doğu Batı Yayınları

Karasar, N. (2013), Bilimsel Araştırma Yöntemi, Ankara: Nobel Yayınları

Kaleva, D. (2012). Patronage Through Dissemination: Louise Hanson-Dyer's Patronage of Gustav Holst, A Journal of Music Research, Vol 37, pp.77-91

Mauss, M. (2005), Bağış (Hediye) Üzerine Bir Deneme-Arkaik Toplumlarda Mübadele Biçimi ve Nedenleri-Sosyoloji ve Antropoloji, Ankara, Doğu-Batı Yayınları

Sönmez, V. ve Alacapınar, F. G. (2011). Örneklendirilmiş Bilimsel Araştırma Yöntemleri. Ankara, Anı Yayıncilik.

Tatlısumak, U. (2016), Osmanlı Ulemâsı ve Patronaj İlişkisi, Selçuk Üniversitesi, Sosyal Bilimler Enstitüsü, Yayımlanmamış Doktora Tezi

Tekin, D. (2003), Yavuz Sultan Selim’e Yazılan Bir Kitâb-1 Edvar, İstanbul Teknik Üniversitesi, Sosyal Bilimler Enstitüsü, Yayınlanmamış Yüksek Lisans Tezi.

\section{Extended English Summary}

Patronage has been the greatest source of support for art and the artist for centuries. The greatest support of art and artist has been the patronage of the palace and noble in almost every civilization starting from ancient Rome until today. Patronage, which is one of the most important factors in the development of the art of music, has become functional as a support policy adopted by religious institutions in some civilizations. Many artists whose name was given importance in the history of music continued their vital activities through patronage. The most basic way to keep the art and the artist alive and to give productions has been patronage until the modern ages when the art of music gained professional status.

In the history of Turkish music, one of the most important supporters of the artist was the palace and the driving force that encouraged the artist to produce the product was patronage just like in Europe. The rulers and the bureaucratic group supported the music educator, composer and performer financially and morally at every opportunity. The aid and the opportunities granted to these people were reflected in both the Ottoman literature and the official correspondence of the Ottoman state. So much so that the Ottoman archives are rich in terms of documents that can concretely describe the subject of patronage.

This research focuses on art patronage and artist patronage in Turkish music culture in general and tries to provide an overview of Ottoman archival documents on the subject of patronage applied both to public and non-public musicians throughout the history of Turkish music.

The subject of patronage, which is of great importance in the development of the art of music in Turkish history, has been handled within the scope of the research and archive documents regarding the reflection of the patronage practice in the history of music have been gathered together. Based on these documents; firstly, it has been tried to clarify which practices are made within the 
Feyzi, A., \& Sümbüllü, H. T. (2019). Patronaj ve müzik ilișkisi açısından Osmanlı arșiv belgeleri üzerine bir durum değerlendirmesi. Journal of Human Sciences, 16(4), 1038-1050. doi:10.14687/jhs.v16i4.5882

scope of patronage in the history of Turkish music. In addition, the musicians people or groups who undertook the benefit of this application, what kind of benefit from this phenomenon of the artist benefiting from the patronage of this phenomenon, the patronage-artist relationship in the name of these practices made on behalf of the patronage of musicians practices in the process of professionalization of the process of professionalization and how it affected socioeconomic aspects of the related musicians thanks to the practices made, how the practices related to the patronage of musicians made during the Ottoman period were transferred to the Republican period, and to what extent the patronage was reflected in the Ottoman written literature.

The data received mainly in the research process, archive documents related to patronage and found music relationship in the Ottoman archives in Turkey have been achieved with the screening method. These archive documents collected in the common repository were examined by document analysis and classified into categories. The categories in which these archive documents are classified have been handled as phenomena in which the patronage practice in Turkish music culture is heavily reflected. Taking into consideration the place of the mentioned categories in Turkish music culture, the effects of the patronage phenomenon on the development of Turkish music culture are tried to be outlined in general terms. Samples of the classified archive documents are given in the research with their identification numbers. As a result of the field research, it has been tried to draw attention to the density of the documents related to the patronage issue in the Ottoman archives.

Considering the contents of the documents in the archives; the reflections of the patronage phenomenon on Turkish music were observed to be in two different directions in two different periods. Patronage application was understood to be different in terms of application before and after 19th century. Before the 19th century, it was seen that the patronage of the palace was mostly used for local musicians and music organizations affiliated with the palace. After the 19th century, it was understood that the section that benefited from the phenomenon of patronage in parallel with the bureaucratic westernization was generally used for foreign musicians and foreign music institutions that were not Ottoman people. It is noteworthy that the number of documents found in the archives was intensely concentrated after the 19th century. 